\title{
PANDEMIC AND RECENT TRENDS IN BALANCE OF PAYMENTS: THE CASE OF GEORGIA
}

\author{
NANA ASLAMAZISHVILI \\ $\mathrm{PhD}$ in Economics, Invited Professor \\ Ivane Javakhishvili Tbilisi State University, Georgia \\ aslamazishvilinana@gmail.com
}

\begin{abstract}
Many countries suffer from Balance of Payments deficits. However, proper analysis is needed to determine how systemic, strategically balanced, and objective it is. The pandemic has proven to be an excellent diagnostician for assessing the robustness of current economic strategies in general and in relation to the Balance of Payments. It, like the litmus paper, highlighted the strengths and weaknesses of the economic strategies implemented by the countries. And that should be the main lesson the world has learned from the pandemic.

Georgia, with persistent Balance of Payments deficit, is becoming increasingly vulnerable to global changes caused by pandemic processes. The current account deficit in 2020 was 12.5 percent of GDP, up from 5.5 percent in 2019. The development of a worse-case scenario for the growth of the deficit was significantly hampered by the increase in remittances inflows, which was less expected in the context of global lockdowns around the world. However, in reviewing developments over the last two decades, the paper finds that the still-high dependence of current account on remittances continues to maintain the volatility of Balance of Payments. Moreover, favorable conditions for the development of international tourism in the country have raised high expectations for this activity, although this sector is very sensitive to a number of external and global factors, as confirmed by the current pandemic. Thus, the article recommends considering international tourism as an additional source of foreign exchange inflows into the country, and not as one of the main and decisive ones.

The deterioration of the Balance of Payments and the reduction of foreign exchange earnings create unfavorable prospects in terms of dealing with growing international financial liabilities. According to 2020 statistical data, the country's international financial liabilities were 2.3 times higher than GDP, of which debt liabilities - 129.9 percent of GDP, while the total foreign exchange inflows of the Balance of Payments, which are intended to serve these liabilities, in the same year amounted to only 55.4 percent of GDP. These data show that there are no alternatives to choosing the right strategy for achieving a reasonable relationship between trajectories of external liabilities and foreign exchange earnings, taking measures to improve the Balance of Payments.

The purpose of this article is to clarify the nature of the country's Balance of Payments deficit; How realistic the prospect of mitigating the degree of vulnerability to global factors is in a small economy with limited resources; How we can turn a problem into an opportunity. On the other hand, it is unknown when the crisis, known as COVID-19, will stop finally, it is important to critically evaluate both the pros and cons of given economic policy "... in order to make the economic development agenda more rational, responsive, results- and long-term perspectives oriented" (Aslamazishvili, 2020).
\end{abstract}

KEYWORDS: BALANCE OF PAYMENTS, CURRENT ACCOUNT, TRAVEL, REMITTANCES, PANDEMIC, COVID-19.

For citation: Aslamazishvili, N., (2021). Pandemic and Recent Trends in Balance of Payments: The Case of Georgia. Globalization and Business. 12, 94-102. https://doi.org/10.35945/gb.2021.12.013

\section{INTRODUCTION}

Without any bias, it can be said that the Balance of Payments, as a statistical tool for data analysis, is a kind of combined measurement for assessing both domestic and foreign economic policy of the country. Moreover, even an empirical analysis of events clearly shows that in the context of a global pandemic, the correctness of both short-term and long-term visions of economic policy is comprehensively reflected in the Balance of Payments.

On the other hand, it can be said without exaggeration that the pandemic proved to be an excellent diagnostician in assessing the reliability of current economic strategies. It, like the litmus paper, highlighted the strengths and weaknesses of the economic strategies implemented by the countries. And that should be the main lesson the world has learned from the pandemic.

What lessons did Georgia learn from the pandemic?

\section{Recent noteworthy trends in Balance of Payments}

It can be said unequivocally that by 2020 it would have been difficult to develop a hypothetical development scenario that would have made such a comprehensive diagnosis of our current social and economic condition, past mistakes in 
Figure 1. Georgia: Dynamics of Current Account and its components, mIn USD

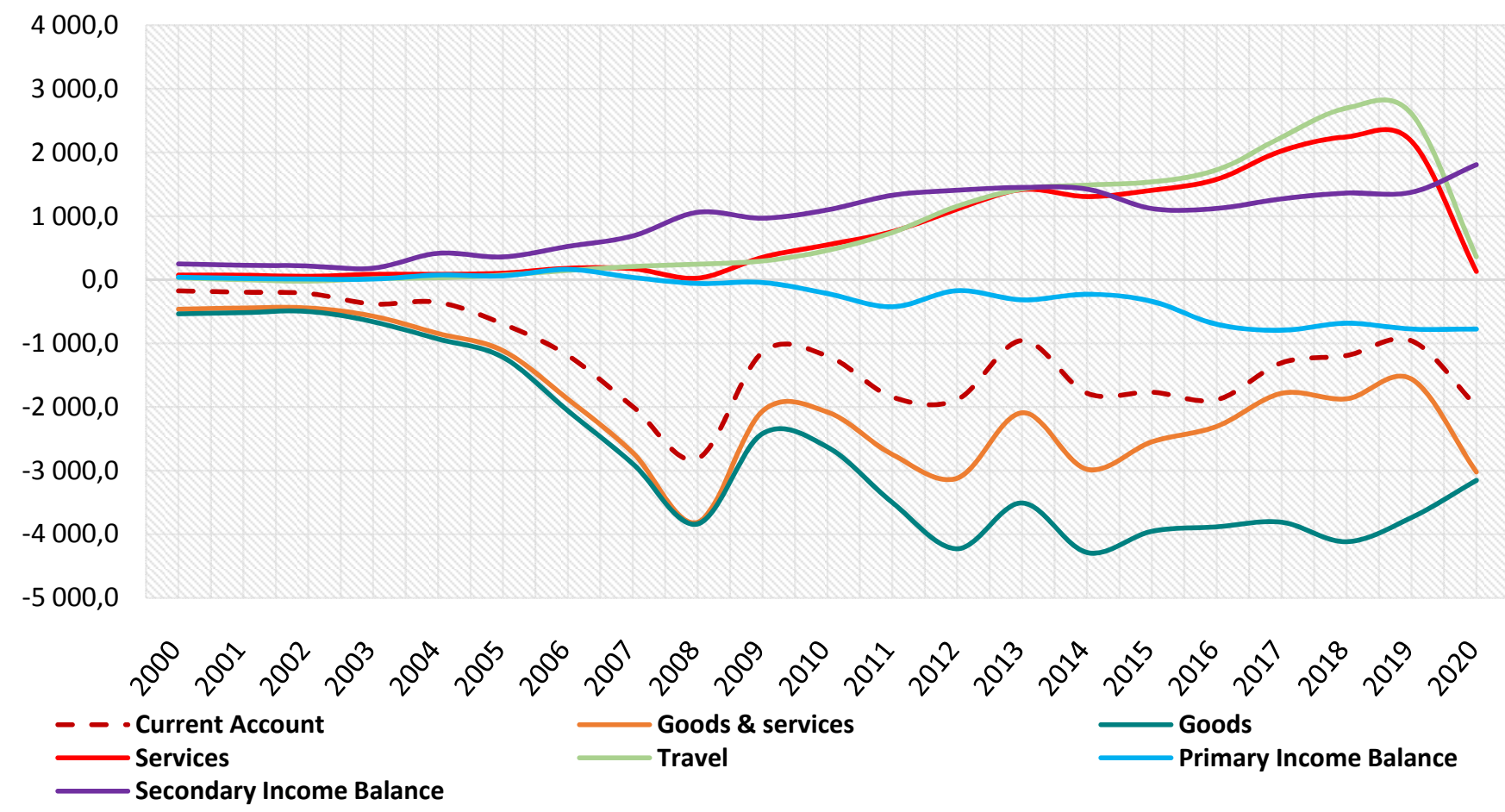

Source: National Bank of Georgia.

economic policy, the appropriateness of the vector of the future development, etc. as the pandemic did.

The current account deficit in Georgia in 2020 amounted to USD -1.99 billion, which was 2.1 times higher than in 2019.

Such a dramatic deterioration in the current account deficit is directly related to the pandemic and global lockdowns, which led to a catastrophic decline in tourist flows, and it was this factor that had a decisive impact on the growth of the current account deficit. Revenues from tourism, which has been a significant contribution in recent years in terms of improving the Balance of Payments, fell by 7.2 times in 2020 compared to 2019, almost 22 percent behind the same figure 10 years ago.

It should be noted that the balance of services before 2007 was characterized by a small positive trend and its volume averaged 1.9 percent of GDP. After a sharp decline in 2008 , in 2009-2013, precisely at the expense of the growth of tourism services, it grew by leaps and bounds, and in 2013 its volume exceeded the pre-war (2008) level by 8.2 times. Until 2019, it continued to grow again about 1.1 times a year,

Figure 2. Georgia: Net Incomes from International Travel, mln USD

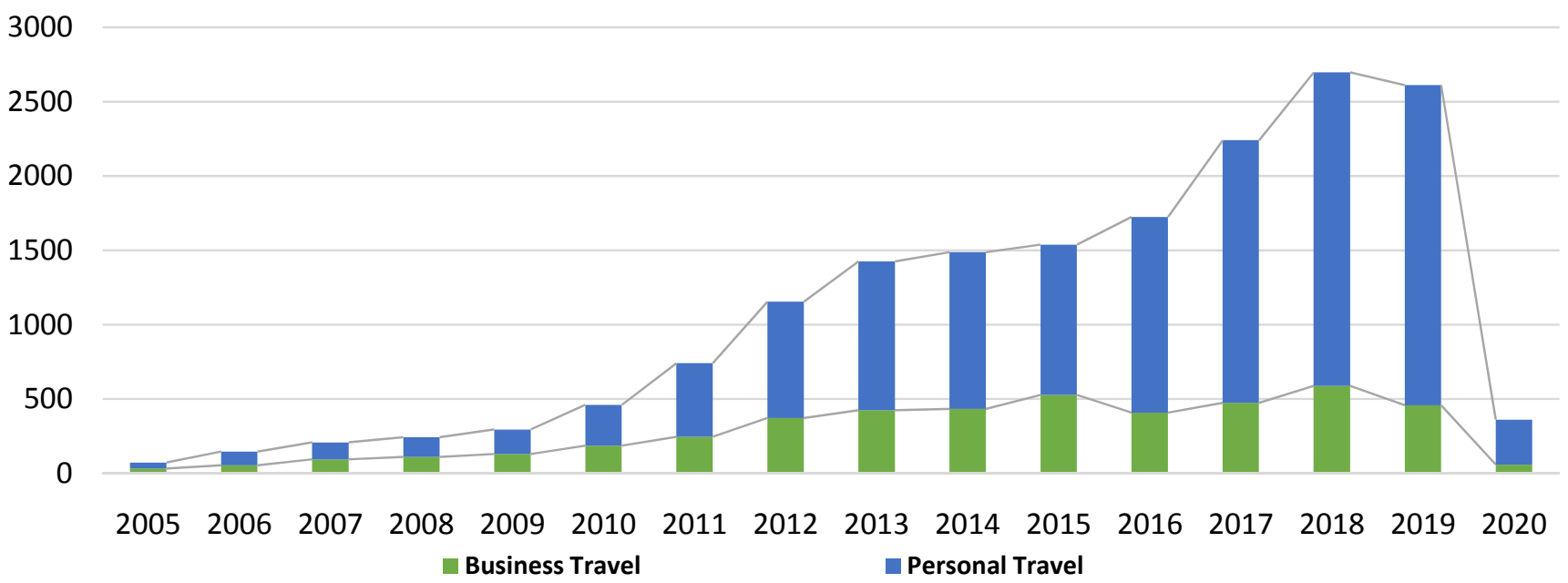

Source: National Bank of Georgia. 
Figure 3. Georgia: Dynamics of Service Account, mln USD

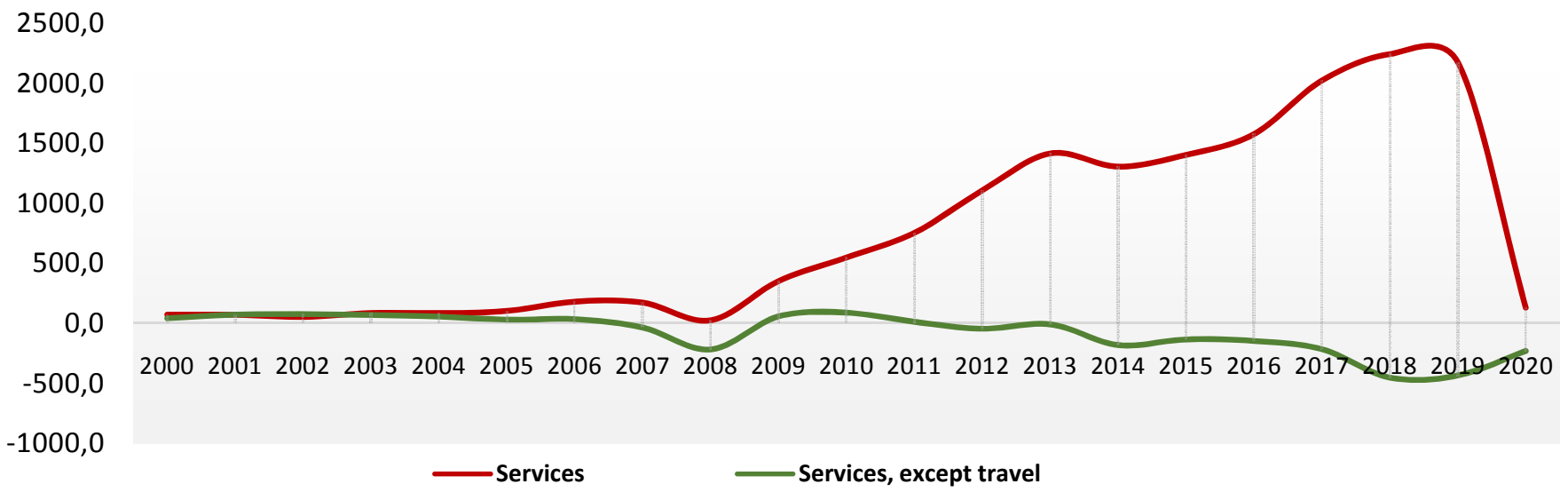

Source: National Bank of Georgia.

compared to the previous year. In 2020, amid a pandemic, it fell catastrophically. In particular, it fell 16.4 times to a similar rate in 2019 and stood at 0.8 percent of GDP, up from 12.5 percent in 2019. This was due to the dramatic decline of the tourism sector due to the collapse of international tourism flows caused by the pandemic.

It is noteworthy that in 2019, in terms of the share of revenues from the export of tourism services in the country's GDP, Georgia ranked 9th in the world (after the island states) with a share of 20.3 percent (https://www.theglobaleconomy.com/ rankings/international_tourism_revenue_to_GDP/). In terms of the share of tourism exports in services exports $(71.0 \%)$ Georgia ranked 25th place and significantly ahead of countries such as Australia (64.4\%), Portugal (51.3\%), Spain (50.7\%), Turkey (46.9\%), Greece (45.2\%), Morocco (42.3\%), Italy (40.5\%). However, in the same countries in 2020 this figure decreased by an average of 19.2 percentage points, and in Georgia - by 36.9 percentage points (https://data.worldbank.org).

Figure 3 below illustrates the contribution of revenues from tourism exports to the Balance of Payments service account of the country and also shows how vulnerable this sector is to external factors. Consequently, this empirical analysis makes it clear that in the long term, the tourism sector should be seen primarily as a source of additional economic growth and, to a lesser extent, as a strategic sector and a some kind of guarantor of stable foreign exchange earnings. Such a realistic approach will greatly reduce the sharp fluctuations of key macroeconomic indicators under the influence of external factors.

The focus on tourism is due, first of all, to the fact that among the surplus items of the country's Balance of Payments, it has been one of the most important in recent years, which is clearly shown in Figure 4 . The catastrophic decline in these revenues in $\mathbf{2 0 2 0}$ was a completely dramatic reversal of the current account positive trend that started in 2017 (see Figure 1).

Of course, many countries suffer from a Balance of Payments deficit. However, a complex analysis of statistical data is needed to determine the nature of the factors causing the deficit, i.e. how systemic they are, how strategically balanced, how objective, and so on.
If we look at the structure of surplus and deficit items in Georgia's Balance of Payments and the dynamics of the latter's recent development, we will see clearly how fragile and vulnerable the Georgian economy is to external factors and how much it is dependent on imports (Figure 4).

In general, of the numerous items in the Balance of Payments, in the case of Georgia, the surplus item is four only. As Figure 4 shows from these four items - Travel, Personal transfers, Compensation of employees from nonresidents, and Pipeline and Electricity transmission, the first three are extremely vulnerable to external factors, unlike the last of them. This was clearly confirmed during COVID-19. In addition to the sharp decline in tourism revenues, as discussed above, the volume of compensation of employees (net) from nonresidents (Figure 5) has also sharply decreased: in 2020, compared to 2019 , this figure decreased by 1.7 times, or USD 318.4 million.

Revenues from pipelines remain stable: in 2020, such revenues amounted to USD 325.4 million - 2.5 percent more than the previous year. It should be noted that the share of exports of pipeline services in the volume of total exports services amounted to 20.5 percent in 2020, instead of 6.9 percent in 2019 (due of reduced revenues from tourism).

The only positive Balance of Payments item that not only decreased but even increased in a pandemic period was personal transfers. However, this growth is generally difficult to assess as a positive trend, as it is related to the shortage of jobs in the country, the acute economic and social problems associated with it, and labor migration. In other words remittances have high human costs. Improving and / or maintaining the current account in this way can be called a paradox of the Balance of Payments, as the aggravation of economic and social problems in the country and labor emigration contribute to the positive development of the current account. This is a typical phenomenon for developing countries (Ratha, 2020). The more acute these problems are in a country, the more likely it is that the volume of personal transfers will increase and, other things being equal, the current account will improve.

At the same time, it should be noted that the increase in such remittances is often associated with increased confi- 
Figure 4. Georgia: Main surplus and deficit items of Balance of Payments, mln USD

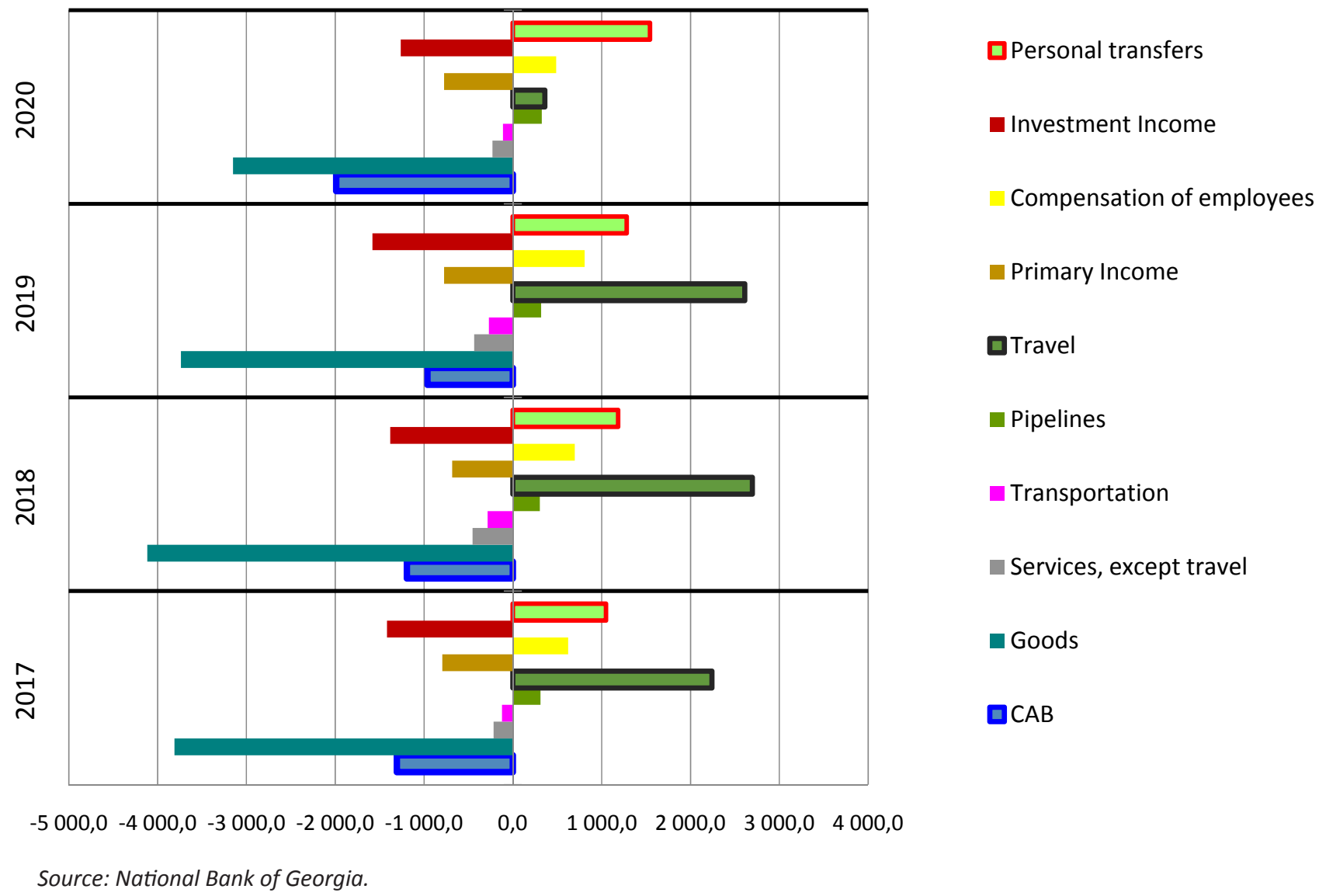

dence in the relevant financial institutions, as well as with a decrease in the transaction cost of remittances, which are important factors in relation to Georgia. For example, in 2020, the average transaction cost of sending remittances to Georgia was 1.1 (as a percent of principal of remitting USD 200), which was the lowest rate after a similar one for Azerbaijan $(1.0 \%)$.

However, there are a number of publications on how remittances, as a result of rising aggregate demand and the resulting expansion of production, are damaging the environment. The same can be said about the increase in imports and the deterioration of the foreign trade balance due to remittances (e.g., Straubhaar \& Vădean, 2006). Such a "threat" has not been observed in Georgia yet. Most of the remittances are personal transfers. Various studies on their use show that beneficiaries in Georgia spend most of their money received from their emigrant relatives on daily necessities, treatment and medicines, paying off debts, as well as financing their studies. There are no signs of an environment conducive to investing in such remittances, although there are good practices of this in many countries. What is the basis for sharing this experience is also evidenced

Figure 5. Georgia: Dynamics of Personal Transfers and Compensation of Employees from Abroud, mln USD 2000,00

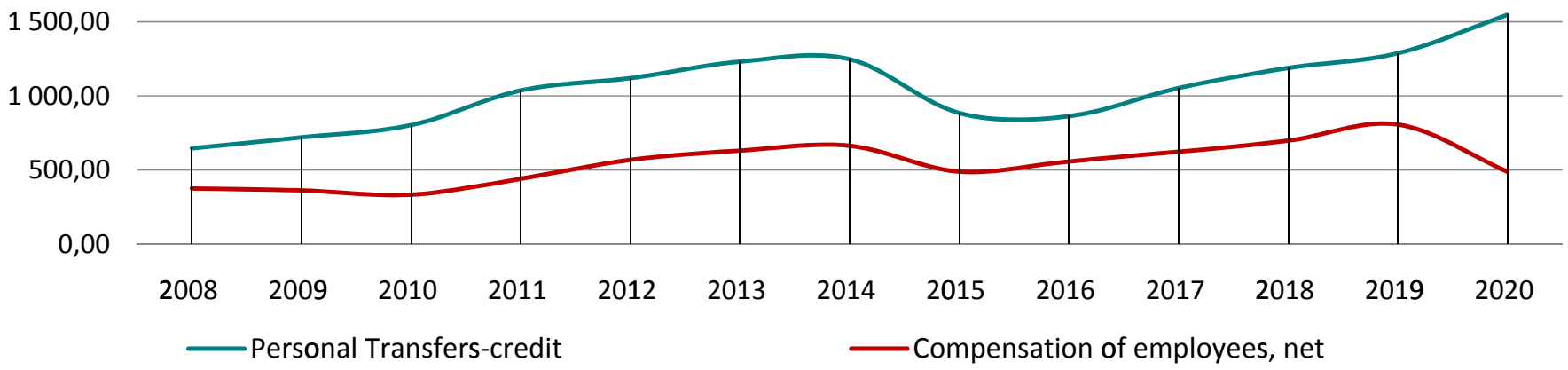

Source: National Bank of Georgia. 
Figure 6. Average transaction cost of sending remittances to a specific country (\%) - Georgia, Armenia, Latvia, Moldova

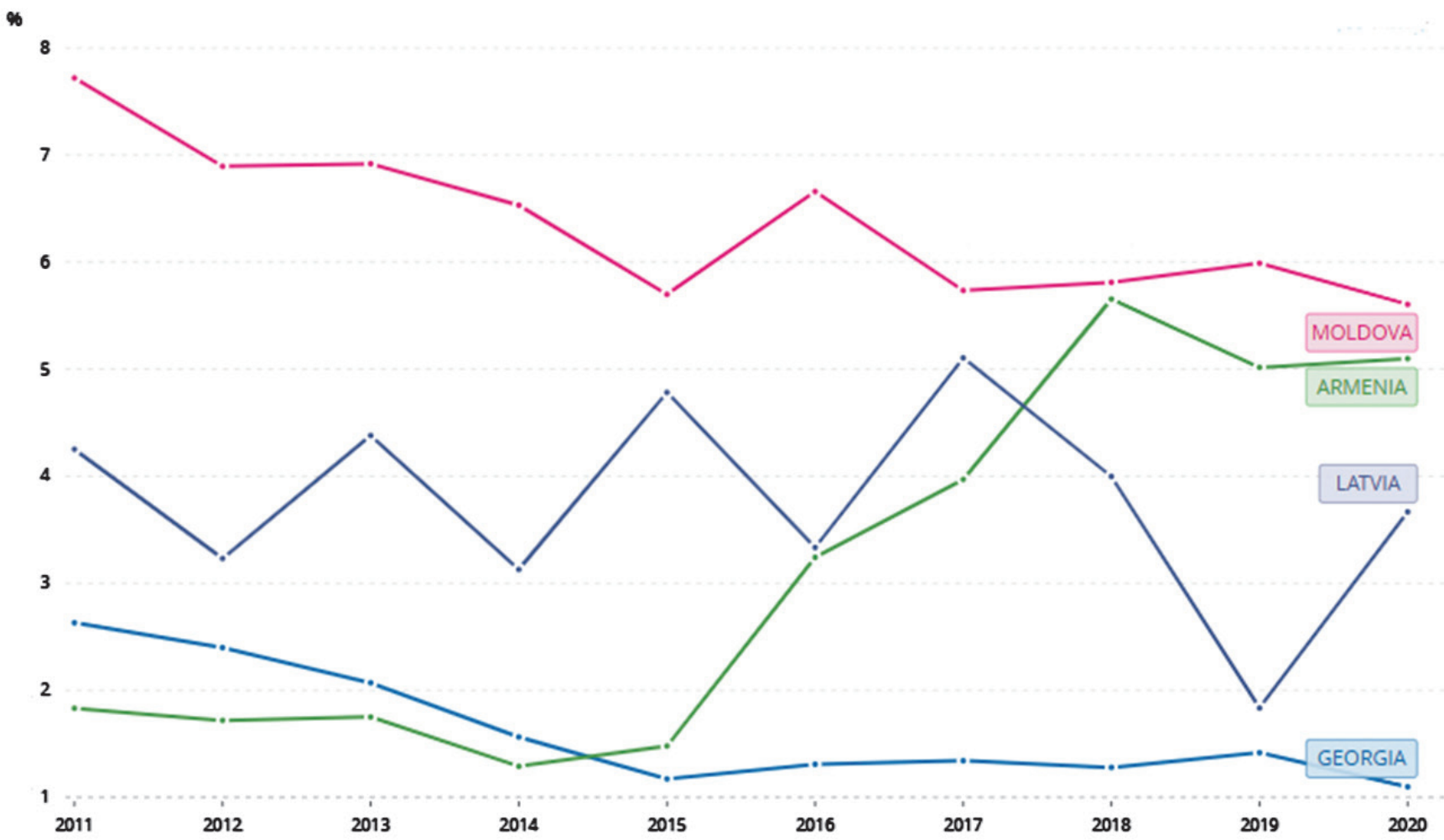

Source: https://data.worldbank.org/indicator/SI.RMT.COST.IB.ZS?contextual=default\&locations=GE-AM-LV-MD\&view=chart

by the fact that personal transfers to our country are quite high in relation to GDP. Even in a pandemic, in 2020 this indicator was 13.3 percent. For comparison, below is Figure 7 , which shows the ratio of personal transfers to GDP for selected countries and groups of countries.

To better understand the scale of personal transfers in Georgia, it is enough to compare it with the volume of foreign direct investment. In particular, by 2020, the volume of inbound personal transfers was 2.5 times higher the volume of inbound foreign direct investment (see Figure 8).

The difference between the current account calculated with and without personal transfers has sharply increased since 2009 (see Figure 9), and it has remained since then. As statistics show, the current account in 2020, without personal transfers, would be 1.8 times worse than the current one: It would be USD -3.54 billion instead of USD -1.99 billion, i.e. the deficit would be $22.2 \%$ instead of 12.5 percent of GDP, which is a critical issue due to several factors.

Firstly, these are Georgia's relations with countries of emigration, which may develop in an unfavorable direction (for example, with Russia) and cause a reduction in remittances;

Second, the pandemic and its economic impact on both the local and global economies remain unpredictable, yet job losses and declining incomes may affect the earnings of our expatriate compatriots;

Third, a number of experiences show that crises in general are not easily predictable and / or easily overcome. Consequently, our donor compatriots abroad are vulnerable to such events;

Fourth, with the change of generations and their behav- ioral culture, the attitude of the emigrated young generation towards sending money to Georgia may change.

At the same time, if the deficit of jobs continues to remain stable and is not overcome at a rapid pace, already in the medium term, the country's prolong chronic current account deficit will reach alarming proportions. Therefore, without maximum concentration on this problem, the risk of irreparable consequences is very high.

Thus, the increase in the scale of the country's current account dependence on remittances and, consequently, personal transfers is undoubtedly an alarming signal. Especialy when the chronic deficit of goods and primary income balances remains the "Achilles' heel" of Georgia's Balance of Payments. In particular:

- If we look at the dynamics of the last two decades, the foreign trade balance continued to decline again after a slight improvement in 2009, and its deficit remained at the average level of 2008 (on average USD -3.8 billion) during 2010-2019; In 2020 alone, it fell to USD -3.2 billion; However, it is likely that even such a small improvement in the foreign trade balance is largely the result of the supply chain disruption caused by the pandemic.

- The ratio of imports to exports has hardly changed and has remained in the range of about 1.7-2.1 in favor of imports over the last 20 years (except in 2007-2008, when these ratios were 2.4 and 2.6, respectively).

- Exports of goods are still focused on raw materials; 
Figure 7. Inward Personal Transfers to GDP (\%) by selected countries, 2020

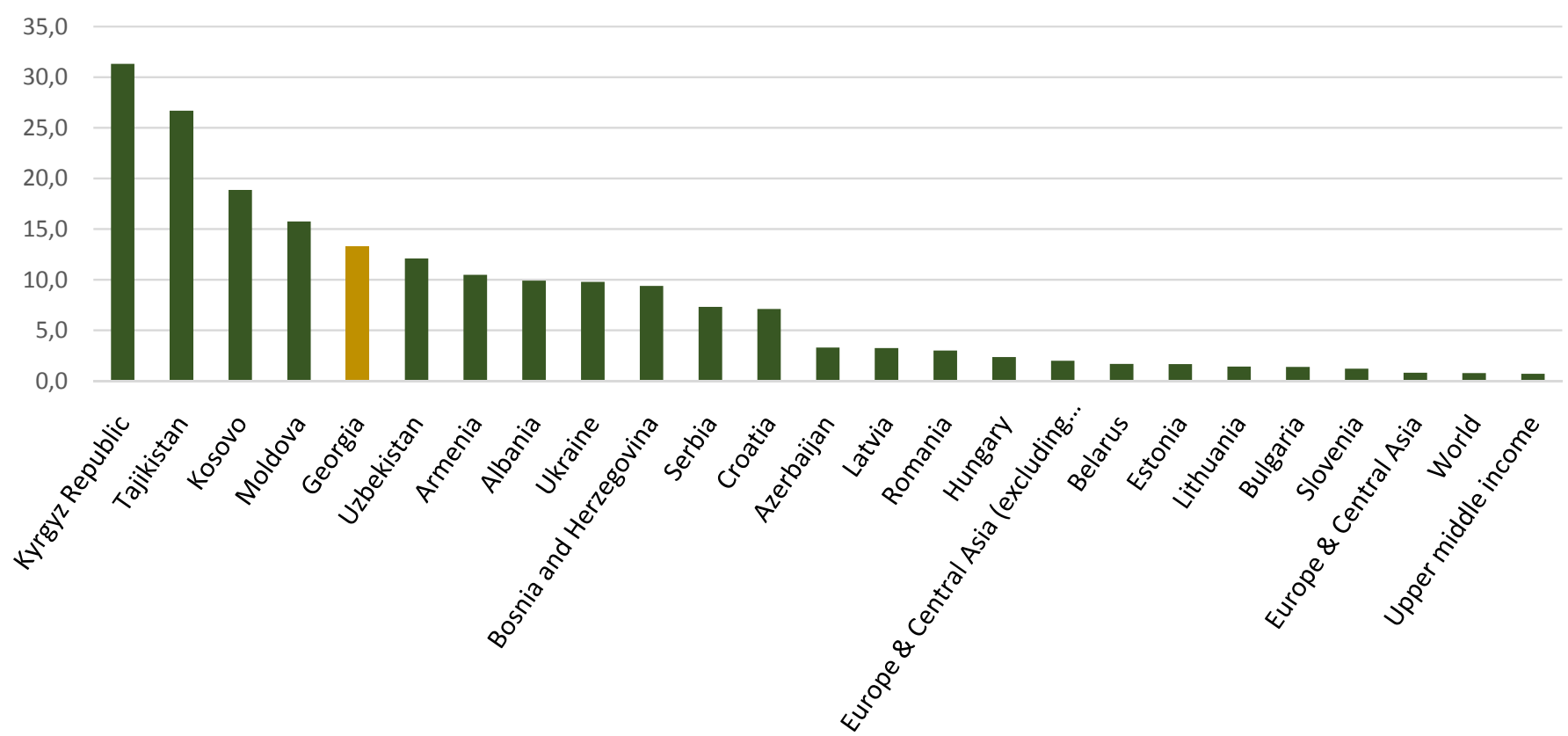

Source: https://data.worldbank.org/indicator/BX.TRF.PWKR.DT.GD.ZS

The share of high-technology products in manufactured exports is insignificant - only 2.57 percent (according to 2019 data), when in 1999-2006 the figure was 27.0 percent per year on average, and in 2002 - even 41.1 percent (www.theglobaleconomy. com/rankings/high_tech_exports/). Although the share of foreign direct investment was high during this period, both in terms of GDP and the total volume of investments in the country (gross fixed capital formation; GFCF) (Figure 11). The situation is worse in terms of information technology exports: only 0.4 percent in total goods exports.

- A decrease in exports revenues, on the one hand, and an increase in external liabilities, on the other, negatively affect the primary income account of the Balance of Payments, the deficit of which increases from year to year due to an increase in investment payments (see Figure 12).

Like the Balance of Payments, the Net international Investment Position of the country is persistently deficient also, reaching USD -24.9 billion in 2020 , or 156.9 percent of

Figure 8. Georgia: Dynamics of Inward Personal Transfers and FDIs, mln USD

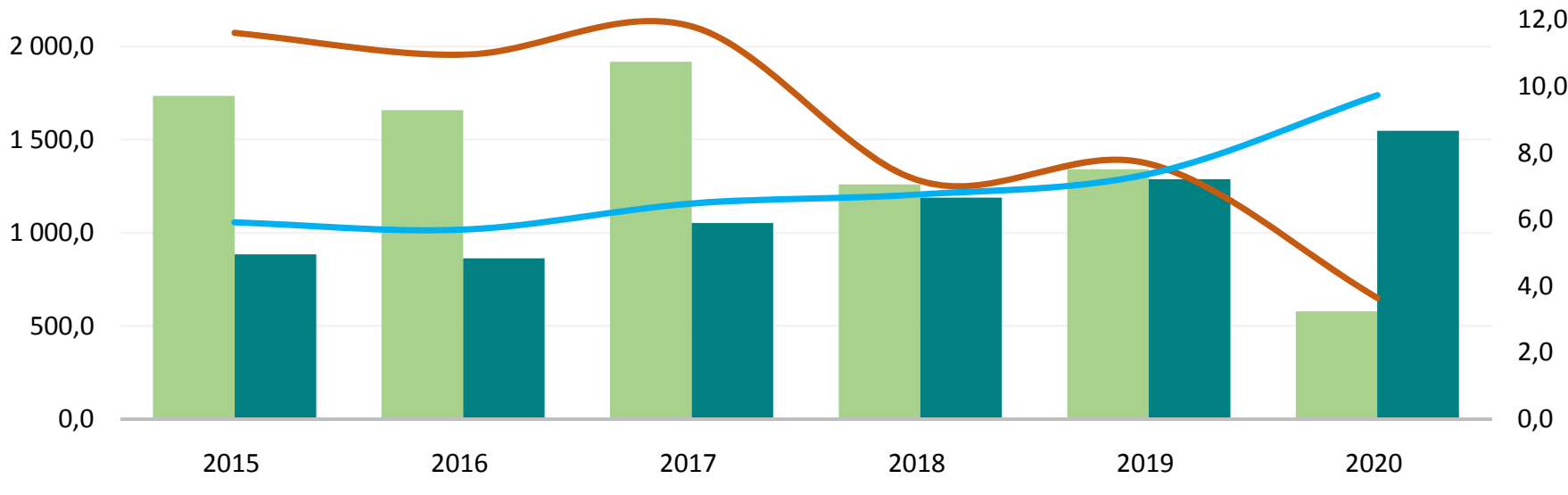

FDI (left scale) Personal transfers (left scale) —FDI to GDP, \% (right scale) — Personal transfers to GDP, \% (right scale) 
Figure 9. Georgia: Dynamics of Current Account, MIn USD

200020012002200320042005200620072008200920102011201220132014201520162017201820192020

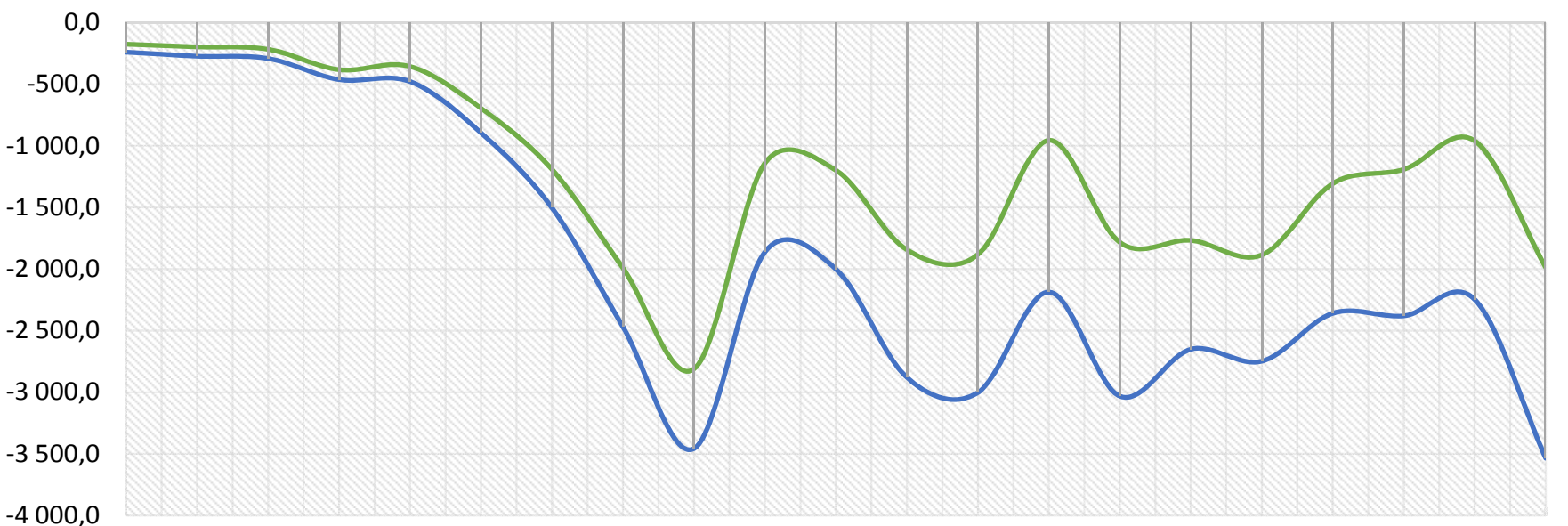

Current Account

Current Account, except personal transfers

Source: National Bank of Georgia.

GDP. A particularly sharp jump in this rate started in 2010 and acquired an alarming scale (see Table 1), which sharply worsened the primary income balance, and this dynamic is likely to be maintained at least in the medium term due to several factors.

In particular, according to data for 2020, the country's international financial liabilities were 2.3 times higher than GDP, of which debt liabilities - 129.9 percent of GDP, and the total foreign exchange earnings of the Balance of Payments, which should serve these liabilities, in the same year amounted to only 55.4 percent of GDP. Thus, even these few data indicate the need for fundamental structural changes in the economy in order to make a major breakthrough in the export sector, in order to service external liabilities and reduce them at an appropriate rate. The analysis of these issues is the subject of a separate study, which definitely requires permanent attention.

\section{CONCLUSION}

The dynamics of the Balance of Payments deficit and the observation of the long-term trajectory of its individual items suggest that no systemic and effective ways of its improving have been found to date, which would fundamentally change its structure, weaken the impact of vulnerable factors on it, and mitigate the risks of its deterioration.

Particular attention should be paid to the country's foreign trade balance and export structure in terms of quality, without of which it will be impossible to overcome the foreign trade deficit dramatically.

In the long run, the tourism sector should be considered primarily as a source of additional growth in exports in services and less - as a strategic sector and a guarantor of stable foreign exchange earnings. Such a realistic approach will greatly reduce the sharp fluctuations of key macroeconomic

Figure 10. Georgia: Import-Export coverage ratio, 2000-2020

3,0

2,5

2,0

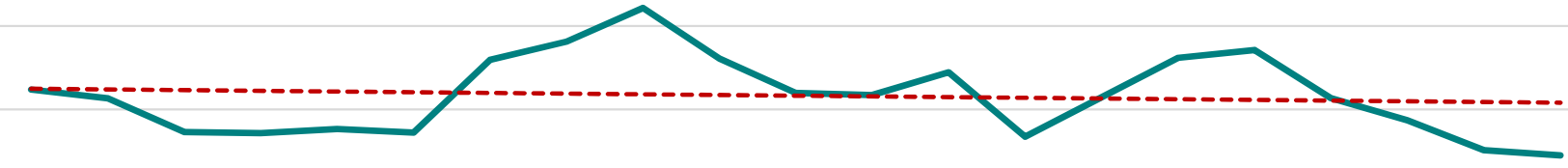

1,5

1,0

0,5

0,0

200020012002200320042005200620072008200920102011201220132014201520162017201820192020

Source: National Bank of Georgia and own calculations. 
Fugure 11. Georgia: The relationship between Inward FDI and High-technology export, \%

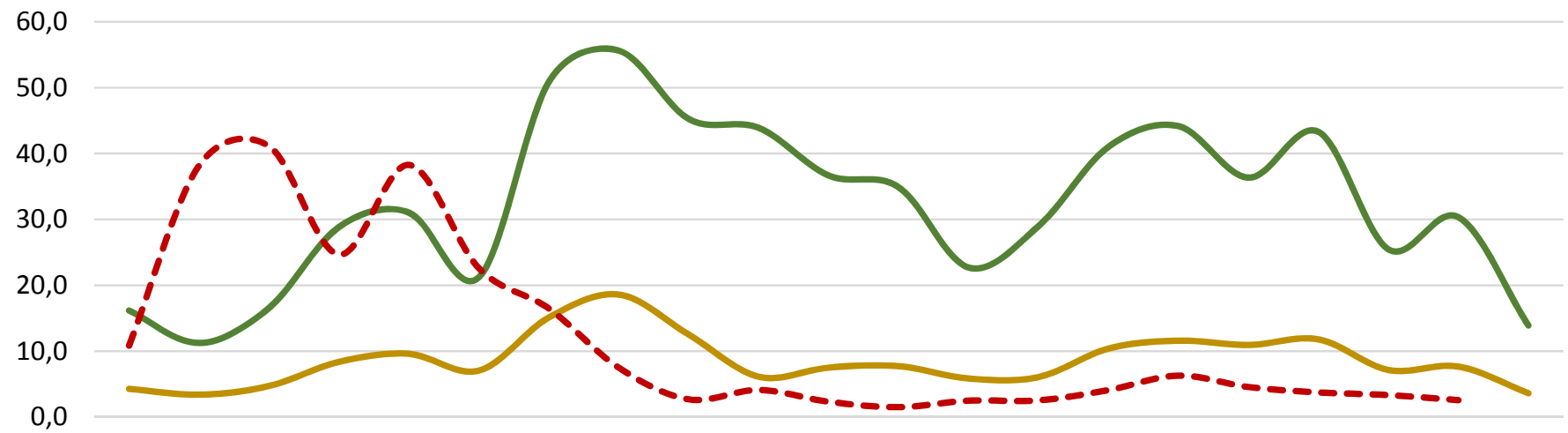

200020012002200320042005200620072008200920102011201220132014201520162017201820192020

FDI to GDP $\quad$ FDI to GFCF _ _ - - High-technology export to manufactured export

Source: National Bank of Georgia; https://data.worldbank.org/indicator/NE.GDI.TOTL.CD?locations=GE

Figure 12. Georgia: Primary Income Balance by Components, $\mathrm{mln}$ USD

1000,0

500,0

0,0

$-500,0$

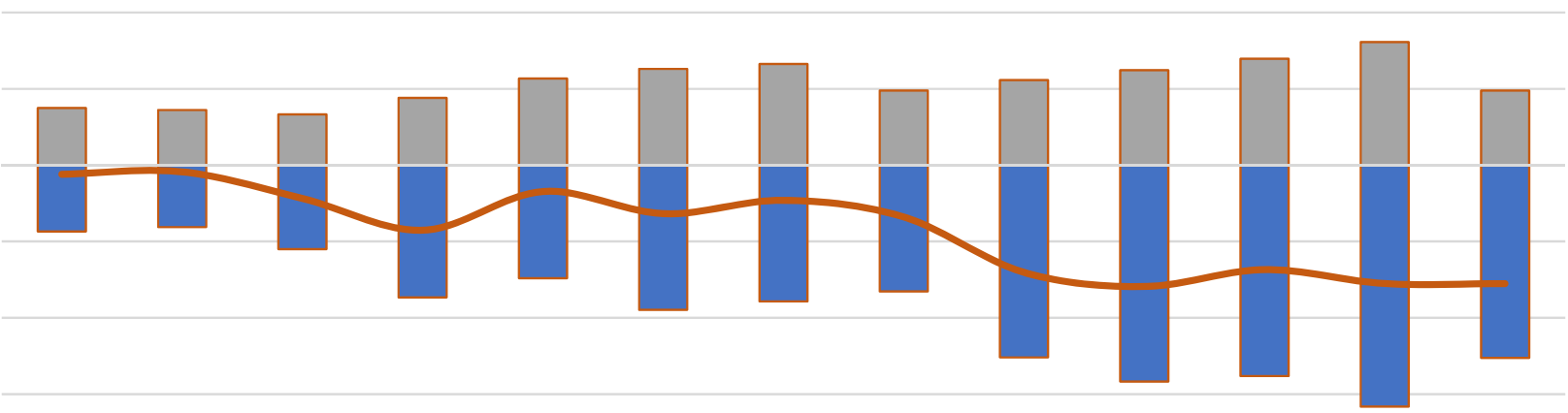

$-1000,0$

$-1500,0$

$-2000,0$

$\begin{array}{lllllllllllll}2008 & 2009 & 2010 & 2011 & 2012 & 2013 & 2014 & 2015 & 2016 & 2017 & 2018 & 2019 & 2020\end{array}$

Investment income, net

$\square$ Compensation of employees, net

Primary Income Balance

Source: National Bank of Georgia.

indicators under the influence of external factors.

Personal transfers remain the most important contributor to the country's Balance of Payments, accounting for 17.7 percent of current account revenues in 2020. However, an alarming signal is the growing dependence of the current account on remittances and, consequently, personal transfers.

In parallel with the dramatic growth of the country's international financial liabilities, there are no clear ways and means of increasing foreign exchange earnings in the near and even medium term, which would ensure the servicing of these obligations.
There are no government programs that would facilitate the investment of remittances and provide some guarantees of a dignified old age for people, who have served to reduce the country's Balance of Payments deficit for years with their remittances.

One of the clear lessons to be learned from the pandemic should be that the concept of economic recovery should acquire qualitatively new content and the relevant process should be focused on serious structural changes in many areas and revolutionary transformations in all areas of society.

Table 1. Georgia: Net International Investment Position to GDP, \%

\begin{tabular}{|l|l|l|l|l|l|}
\hline & 2000 & 2005 & 2010 & 2015 & 2020 \\
\hline Net International Investment Position to GDP & -70.0 & -60.9 & -97.8 & -124.1 & -156.9 \\
\hline
\end{tabular}

Source: National Bank of Georgia and own calculations. 


\section{REFERENCES:}

Adams, R. H., Jr., \& John Page, (2003), International Migration, Remittances, and Poverty in Developing Cloud Bank Policy Research Working Paper 3179 (Washington).

Aslamazishvili, N. (2006, October). "Dutch Disease" in Georgian Economy: Current Reality and Potential Threats. Georgian Economic Trends. Georgian-European Policy and Legal Advice Centre, 57-62.

Aslamazishvili, N. (2018). Balance of Payments of Georgia: Key Aspects of its Analysis. Globalization and Business, 6, $136-143$. https://doi.org/10.35945/gb.2018.06.019

Aslamazishvili, N. (2020). Georgia in the World of Coronomics: Threats and Challenges. Globalization and Business, 10, $94-102$. https://doi.org/10.35945/gb.2020.10.012

Balance of Payments and International Investment Position Manual (2009). Washington D.C. IMF.

Dunn, J.C., Billmeier, A., \& Selm, B. (2004). In the Pipeline: Georgia's Oil and Gas Transit Revenues. IMF Working Papers, 209.

Gaganidze, G., \& Ramishvili, B. (2018). How to Evaluate Efficiency of the Export Strategies. International Scientific-Practical Magazine Globalization and Business, 5, 24-30.

https://data.worldbank.org/indicator/SI.RMT.COST.IB.ZS?contextual=default\&locations=GE-AM-LV-MD\&view=chart

https://nbg.gov.ge/statistics/statistics-data

https://www.geostat.ge

https://www.theglobaleconomy.com

Cuc, M. M., \& Lundback, E. J. (2006). Migration and Remittances in Moldova. IMF Special Issues. IMF. https://doi. org/10.5089/9781589064904.058

Papava, V., \& Charaia, V. (2021). The problem of Georgia's public debt growth during the economic crisis caused by the COVID-19 pandemic. Georgian Foundation for Strategic and International Studies. 152.

Ratha, D. (2020, February 24). Remittances: Funds for the Folks Back Home. Finance \& Development. IMF.

Sandu, C. (2015). Implications of the Change in the Balance of Payments and the Situation of Its Components on the Romanian Exchange Rate. Science Direct. Procedia Economics and Finance, 32,763-768.

Straubhaar, Th., \& Vădean, F.P. (2006). International Migrant Remittances and their Role in Development. International Migration Outlook. OECD.

World Investment Report. (2021). Investing in Sustainable Recovery. Unctad. UN, 251

Zubiashvili, T., \& Veshapidze, Sh. (2019). Labor Emigration and Employment in Georgia. 